\title{
Determining the Optimum Heap Height Considering the Irrigation Rate and the Slope of Heap Bed Variations in Miduk Copper Mine
}

\author{
B. FAllahfar ${ }^{a} *$, E. RAhimi ${ }^{a}$, N. MOHAGHEGH ${ }^{b}$ \\ ${ }^{a}$ Islamic Azad University-South Tehran Branch, Department of Mining Engineering, Tehran, Iran \\ ${ }^{b}$ Sharif University of technology, Department of chemistry, Tehran, Iran
}

Determining an optimum height is remarked as one of the most important issues in heap designing and this is obtained by calculating the number and the height of heap lifts. Although the increase of lift height has benefits in heap leaching method from economic point of view, it will reduce the stability and make process problems such as low permeability. The current paper analyzes the effect of sulphuric acid irrigation on the strength parameters of Miduk oxide copper ores. In addition, the result of the process experiments have evaluated with different irrigation rates as well as variable conditions of permeability. From process view, approximately $75 \%$ of copper is recovered at irrigation rate of $8 \mathrm{l} / \mathrm{h} \mathrm{m}^{2}$. Due to the significance of economic and process parameters in determining the optimum height of lifts, these parameters are simultaneously studied. The results are demonstrated that although the increase of irrigation rate and permeability can lead to more copper recovery in this mine, it will remarkably decrease the stable height of lifts. Moreover, changes in the bed slope will have a similar effect on the height of the lifts.

DOI: 10.12693/APhysPolA.128.B-352

PACS: 91.60.- $-\mathrm{x}, 91.65 .-\mathrm{n}$

\section{Introduction}

Determining the optimum heap height is highly considered in heap leaching method and it is important from processing and economical viewpoints [1]. Copper ore is first prepared in agglomeration unit in heap leaching method, and then it is placed on an anti-acid bed made of poly ethylene and clay in an appropriate slope [2]. The situation of heap bed is generally chosen adjacent to the soil dump mass of mine oxide. Next, the diluted sulphuric acid is irrigated over the heap in a certain concentration and irrigation rate, then it is passed through heap and it dissolves the copper in oxide ore and leaves the drainage part and it is directed to extracting and electrolyzing refinery units to recover and supply pure cathode copper [3].

So far, lots of different methods have been presented to analyze the stability of soil slopes, but limit equilibrium method has been identified as one of the most applicable methods in stability analyses of soil slopes including general limit equilibrium method [4], Spencer [5], Morgenstern and Price [6], Low and Karafith [7], Bishop [8], Janbu [9] and, etc. In most of these methods, the stability of slip mass is divided into separate blocks by parallel surfaces and gravity force and the free diagram of the forces exerted on each block is depicted. Consequently, the forces exerted on each block and the safety factor of slip mass is calculated based on the equilibrium between force and moment.

*corresponding author; e-mail: bahadorfallahfar@gmail.com
As the cutting parameters are low between the geomembrane and geo-textile layers, the surface between these two materials are usually of the potential vibrating mass. According to different heap layering and the importance of their processing, it is essential to analyze the stability and specify the potential vibrating mass [10].

Many studies have been conducted on optimizing heap leaching process as well as determining the optimum heap height $[11,12]$. In most of these studies, the optimum height of heap is pondered through processing considerations whereas their stability hasn't been regarded. Liam has studied the relationship between the irrigation rate and heap rate and has introduced it as an indication to evaluate both the recovery rate and optimize the process through processing considerations. He has not contemplated the effect of irrigation rate on structure stability [11]. Pennstrom has also studied the influence of irrigation rate on the optimum management of leaching solution but he hasn't remarked the effect of this issue on structure stability [12].

\section{Heap modelling}

Geo Slope/W software is applied to analyze the heap stability in Miduk copper mine. This software is actually a two dimensional program determining the reliability factor and the probability of levels falling down based on vertical strips method. Furthermore, it is required to model acid seepage in the structure as well as acid balance level in the intended structure to direct this analysis according to the two phases of heap. Seep $/ \mathrm{W}$ is also additional software contributes to model the heap along with the data in Tables I, II and III. 
TABLE I

Data practiced to estimate the curve of soil moisture of Midi heap by Venn John Stein.

\begin{tabular}{c|c|c|c|c}
\hline \hline \multicolumn{3}{c|}{ parameter } & residue & saturated \\
\hline$m$ & $n$ & $a$ & \multicolumn{2}{c}{ moisture [\%] } \\
\hline 0.39 & 1.63 & 0.21 & 7.530 & 36
\end{tabular}

The amount of water and seepage in the saturated conditions of Midi heap layers.

\begin{tabular}{c|c|c|c}
\hline \hline & ore & gravel & geo-memberan \\
\hline water content [\%vol.] & 0.342 & 0.31 & - \\
permeability [m/s] & $10^{-4}$ & $6.24 \times 10^{-4}$ & $10^{-17}$ \\
clogging factor & 1.1 & 1.38 & - \\
long term perm. & $0.91 \times 10^{-4}$ & $4.52 \times 10^{-4}$ & -
\end{tabular}

TABLE III

The parameters required for modelling the layers of leaching structure and the changing rate of resisting parameters of each layer by increasing the special weight and the duration of acid seepage through it. $C=0$.

\begin{tabular}{c|c|c|c|c|c|c|c|c|c}
\hline \hline Height & \multicolumn{3}{|c|}{$3 \mathrm{~m}$} & \multicolumn{3}{c|}{$4 \mathrm{~m}$} & \multicolumn{3}{c}{$5 \mathrm{~m}$} \\
\hline layer & 1 & 2 & 3 & 1 & 2 & 3 & 1 & 2 & 3 \\
\hline$\rho\left[\mathrm{kN} / \mathrm{m}^{3}\right]$ & 17.29 & 17.64 & 17.85 & 17.43 & 17.80 & 17.99 & 17.50 & 17.90 & 18.11 \\
$\varphi$ & 37.15 & 35.62 & 34.73 & 36.52 & 34.99 & 34.09 & 36.10 & 34.50 & 36.60 \\
$\varphi_{b}$ & 24.769 & 23.749 & 23.153 & 24.346 & 23.326 & 22.730 & 24.067 & 22.998 & 22.401
\end{tabular}

\subsection{The effect of acid irrigation speed on stability}

This part reflects the results of the effects of acid irrigation discharge rate on its flow in heap and the simultaneous influence of irrigation rate change on heap stability. Therefore, acid seepage analysis is held in leaching structures in three various irrigation speeds as displayed in Table IV. The analysis of structure stability is conducted by Geo Slope/W software. Results are represented in Table $\mathrm{V}$ and Fig. 1.

As observed, when the irrigation speed increases, the maximum speed and the discharge passing through various levels rises. Conclusively, the acid rate moves up and most of the structure gets half saturated as the acid irrigation speed enhances. Moreover, the increase of saturation degree boosts breaking and reduces heap stability.

\subsection{The effect of slope changes of heap bed on stability rate}

In this part, the effect of slope changes of heap bed on stability rate is scrutinized based on the results from heap stability analysis. So, the heap bed of Miduk copper complex is modelled by 4 different slopes of $3^{\circ}, 4^{\circ}, 5^{\circ}$ and $6^{\circ}$. Then, the layers of copper oxide ore is placed on the bed. Considerably, since there are limitations to optionally practice Geo Slope/W software in changing bed slope, this operation is done by changing the ratio of the bed total height to the bed total length. In this case, the bed slopes increases and the volume of copper oxide soil diminishes. Therefore, this makes problems for the software to do stability analysis. The volume of the oxide soil should be expanded right after the slope of heap bed escalates in order to prevent this problem. And this
TABLE IV

Effect of acid injection velocity changes on the maximum velocity and discharge of drainage layer.

\begin{tabular}{c|c|c}
\hline \hline Discharge through & maximum & irrigation \\
\cline { 2 - 3 } drainage $\left[\mathrm{m}^{3} / \mathrm{s}\right]$ & \multicolumn{2}{|c}{ speed $[\mathrm{m} / \mathrm{s}]$} \\
\hline $1.0741 \times 10^{-3}$ & $2.0635 \times 10^{-3}$ & $5 \times 10^{-6}$ \\
$4.3457 \times 10^{-4}$ & $8.3488 \times 10^{-4}$ & $2 \times 10^{-6}$ \\
$2.1596 \times 10^{-4}$ & $4.1049 \times 10^{-4}$ & $10^{-6}$
\end{tabular}

TABLE V

The results of the stability analysis considering the impact of changes in hips with acid injection velocity (slope: $5^{\circ}$ ).

\begin{tabular}{c|c|c|c|c}
\hline \hline Height & \multicolumn{3}{|c}{ Irrigation speed [m/s] (factor of safety) } \\
\hline $3 \mathrm{~m}$ & $1 \times 10^{-6}(1.488)$ & $2 \times 10^{-6}(1.086)$ & $5 \times 10^{-6}(0.519)$ \\
$4 \mathrm{~m}$ & $1 \times 10^{-6}(1.407)$ & $2 \times 10^{-6}(0.934)$ & $5 \times 10^{-6}(0.468)$ \\
$5 \mathrm{~m}$ & $1 \times 10^{-6}(1.361)$ & $2 \times 10^{-6}(0.815)$ & $5 \times 10^{-6}(0.465)$
\end{tabular}

is done in Miduk copper complex. Finally, results are indicated in Table VI and Fig. 2.

According to the results of a stability analysis is shown in Fig. 2, we see that in general the slope increases, the stability of the heap is reduced. However, by increasing the slope of the bed, looking at the elevation chart looks less safety factor of 1.2. In other words, increasing the slope reduces the height of the heap is stable.

\section{Conclusion}

In the current research, the heap stability of Miduk copper complex is assessed under different processing conditions. This study pondered the simultaneous 


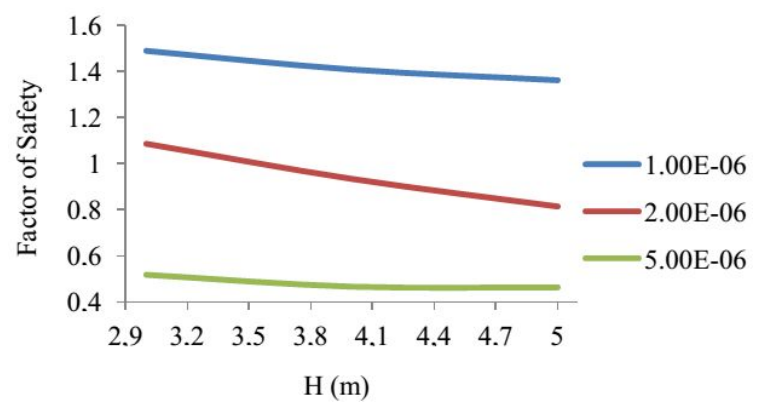

Fig. 1. Safety factor versus height of the lift curves for three different cases of acid injection velocity.

TABLE VI

The results of the stability analysis of structures considering the effect of bed slope changes.

\begin{tabular}{c|c|c|c|c}
\hline \hline Height & \multicolumn{4}{|c}{ Slope of bed [ ${ }^{\circ}$ (f. o. s.) } \\
\hline $3 \mathrm{~m}$ & $3(1.482)$ & $4(1.468)$ & $5(1.407)$ & $6(1.250)$ \\
$4 \mathrm{~m}$ & $3(1.265)$ & $4(1.087)$ & $5(0.934)$ & $6(0.686)$ \\
$5 \mathrm{~m}$ & $3(0.612)$ & $4(0.595)$ & $5(0.468)$ & $6(0.408)$
\end{tabular}

changes of irrigation rate and the slope of heap bed on stability rate. In addition, the results are analyzed by the Bishop limit equilibrium method. The curve of reliability factor is depicted based on lift height regarding the change of acid irrigation rate as well as the change in the slope of the heap bed. It is observed that the increase of irrigation rate makes the structure stability dwindle. This is while; the expansion in the slope of heap bed reflects a similar effect on the structure stability rate. Totally, the lift optimum height is calculated approximately $4.3 \mathrm{~m}$ through analyzing the outcomes from modelling in different situations and remarking the safety factor of 1.2 for heap stability as a temporary structure. Although it is economically important to increase the height of lifts and it makes heap leaching process more beneficial, stability considerations play an important role in determining heap optimum height. Eventually, the heap total height is calculated $38.7 \mathrm{~m}$ by considering 9 lifts during the process life.

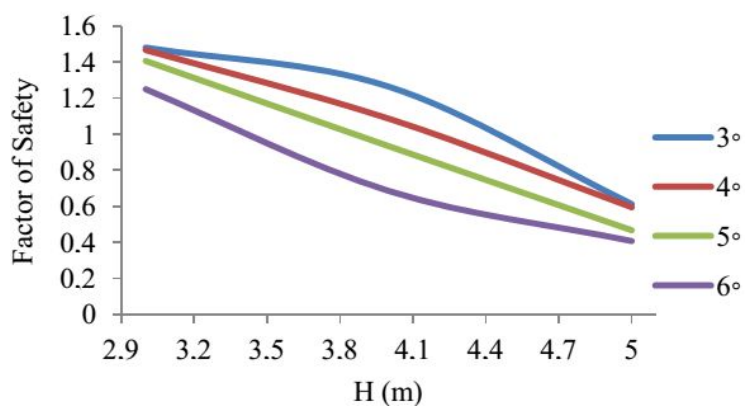

Fig. 2. Safety factor relative to the height of the lift curve, with 4 different modes for the bed slope of heap.

\section{References}

[1] G.A. Padilla, L.A. Cisterns, J.Y. Cueto On the $O p$ timization of Heap Leaching, Technical note, Antofagasta 2008.

[2] M. Rahmani, A. Khodadadi, in: Iranian mining engineering conference, Tarbiat Modarres University, Tehran 2004.

[3] A. Majdi, M. Amini Chermahini, Stability Analysis of Structures Leaching Mass Fractionation Method (new method), College of Engineering, Volume 40, Issue 1, 2006, p. 55.

[4] H. Rahardjo, D.G. Fredlund, General Limit Equilibrium Method for Lateral Force, University of Saskatchewan, Saskatoon 1983.

[5] E. Spencer, Geotechnique 17, 11 (1967).

[6] N.R. Morgenstern, V.E. Price, Geotechnique 15, 79 (1965).

[7] J. Lowe III., L. Karafith, Proc. First Pan-American conference on Soil Mechanics and Foundation, Vol. 2, Mexico City 1960, p. 537.

[8] A.W. Bishop, Geotechnique 5, 7 (1955).

[9] N. Janbu, Proc. of the European Conference on Stability of Earth Slopes, Vol. 3, Stockholm 1954, p. 43.

[10] A.J. Breitenbach, GFR Magazine 22, 1 (2004).

[11] H.M. Lizama, J.R. Harlamovs, D.J. McKay, Z. Dai, Miner. Eng. 18, 623 (2005).

[12] W.J. Pennstrom, J.R. Arnold, Miner. Metall. Proc. 16, 12 (1999). 